University of Wollongong

Research Online

SMART Infrastructure Facility - Papers

Faculty of Engineering and Information

Sciences

2017

Investigating the accuracy of georeferenced social media data for flood

mapping: The PetaJakarta.org case study

Robert Ighodaro Ogie

University of Wollongong, rogie@uow.edu.au

Hugh I. Forehead

University of Wollongong, hughf@uow.edu.au

Follow this and additional works at: https://ro.uow.edu.au/smartpapers

Part of the Engineering Commons, and the Physical Sciences and Mathematics Commons

Research Online is the open access institutional repository for the University of Wollongong. For further information contact the UOW Library: research-pubs@uow.edu.au 


\title{
Investigating the accuracy of georeferenced social media data for flood mapping: The PetaJakarta.org case study
}

\author{
Abstract \\ Georeferenced social media data are gaining increased application in creating near real-time flood maps \\ needed to improve situational awareness in data-starved regions. However, there is growing concern that \\ the georeferenced locations of flood-related social media contents do not always correspond to the \\ actual locations of the flooding event. But to what extent is this true? Without this knowledge, it is difficult \\ to ascertain the accuracy of flood maps created using georeferenced social media contents. This study \\ aims to improve understanding of the extent to which georeferenced locations of social media flood \\ reports deviate from the actual locations of floods. The study analyses flood-related tweets acquired as \\ part of the PetaJakarta.org project implemented in the coastal mega-city of Jakarta and provides insight \\ into the level of accuracy expected with using georeferenced social media data for flood mapping. \\ Importantly, the results reveal that the accuracy of flood maps generated with georeferenced social media \\ data reduces with increase in the size of the minimum mapping unit of the flood map. Finally, an \\ approach is recommended for creating more accurate real time flood maps from crowdsourced social \\ media data.
}

\section{Keywords}

mapping:, flood, data, media, social, accuracy, study, case, georeferenced, petajakarta.org, investigating

\section{Disciplines}

Engineering | Physical Sciences and Mathematics

\section{Publication Details}

Ogie, R. Ighodaro. \& Forehead, H. (2017). Investigating the accuracy of georeferenced social media data for flood mapping: The PetaJakarta.org case study. 2017 4th International Conference on Information and Communication Technologies for Disaster Management (ICT-DM) (pp. 30-35). United States: IEEE. 


\title{
Investigating the Accuracy of Georeferenced Social Media Data for Flood Mapping
}

\author{
The PetaJakarta.org Case Study \\ Robert Ighodaro Ogie, Hugh Forehead \\ Smart Infrastructure Facility \\ University of Wollongong \\ Northfields Avenue, Wollongong NSW 2522, Australia \\ rogie@uow.edu.au
}

\begin{abstract}
Georeferenced social media data are gaining increased application in creating near real-time flood maps needed to improve situational awareness in data-starved regions. However, there is growing concern that the georeferenced locations of flood-related social media contents do not always correspond to the actual locations of the flooding event. But to what extent is this true? Without this knowledge, it is difficult to ascertain the accuracy of flood maps created using georeferenced social media contents. This study aims to improve understanding of the extent to which georeferenced locations of social media flood reports deviate from the actual locations of floods. The study analyses flood-related tweets acquired as part of the PetaJakarta.org project implemented in the coastal mega-city of Jakarta and provides insight into the level of accuracy expected with using georeferenced social media data for flood mapping. Importantly, the results reveal that the accuracy of flood maps generated with georeferenced social media data reduces with increase in the size of the minimum mapping unit of the flood map. Finally, an approach is recommended for creating more accurate real time flood maps from crowdsourced social media data.
\end{abstract}

\section{Keywords—social media; flood; map; geolocation; disaster}

\section{INTRODUCTION}

Flooding remains the costliest and deadliest natural hazard, accounting for $40 \%$ of all natural disasters and half of all disaster-related deaths [1], [2]. Historical records have shown that coastal megacities situated in developing nations suffer the most from flood disasters, mainly due to huge population exposure, and more critically, the lack of actionable data and poor situational awareness that undermine the efforts of flood control operators, first responders and emergency services [3]. In these developing regions, traditional data sources such as remote sensing continue to have limited use due to factors such as cost and the need for an accurate digital elevation model (DEM) that is often lacking in developing nations [4], [5]. In response to this data scarcity problem, there has been a growing effort to explore non-authoritative data sources such as crowdsourced social media data and volunteered geographic information in improving response to urban floods [6], [7], [8]. In that sense, social media sites such as Twitter and Flickr have become powerful and ubiquitous new sources of environmental data, providing unique opportunity to harvest large-scale

This work was funded under the auspices of the Australian National Data Services (ANDS) through the National Collaborative Research Infrastructure Strategy Program [ANDS MODC 15, 2014], the Department of Foreign Affairs and Trade, Australia (DFAT 2014) [Agreement Number 71984], Twitter Data Grant (2014) and the University of Wollongong Global Challenges Program Seed Funding (2014) and Challenges Grant (2015). spatio-temporal data of critical value to managing authorities in coastal communities [6]. This is particularly appealing in a mega-city context, where millions of citizens acting as 'human sensors' on social media platforms can potentially contribute vast amount of time-critical information to help improve situational awareness and decision making during flooding events [7].

During flooding events, situational awareness gleaned from social media data is mainly attained through flood mapping. Several studies (e.g., [6], [7], [8], [9]) have proposed methods of creating near real-time flood maps from social media data, but not all of them have followed the same pathway for determining the location of floods. There is school of thought that believes flood locations can be determined based on reference to place names or physical locations as contained within social media contents [7], [9], [10]. For example, Jongman et al. [9] combined satellite observations of water coverage with tweets containing textual information about flood locations in order to produce daily flood impact maps in the Philippines and Pakistan. Brouwer et al. [10] used Twitter messages that mention locations of flooding during the December 2015 flood in the city of York (UK) to demonstrate how to generate probabilistic and deterministic flood maps, taking uncertainties in the data into consideration. A related work focused on creating and evaluating flood maps for the city of Jakarta, based on Twitter messages containing reference to flood locations [6]. Also using Jakarta as a study area, Eilander et al. [7] proposed a novel flood mapping approach based on a flood fill algorithm that utilizes a Digital Elevation Model (DEM) in combination with tweets containing flood depth and textual reference to flood locations.

Another school of thought believes that when creating flood maps, flood locations can be determined from georeferenced flood-related tweets with exact latitude/longitude coordinates [4], [8], [11]. In 2012, Graham et al. [11] set out to understand how well georeferenced tweets correspond to recorded flooding events. They did so with Twitter data for the UK floods of Nov 20 to Nov 27, 2012 and claimed that concentration of flood-related tweets seems to closely reflect the actual locations of floods [11]. Holderness and Turpin [8] adopted the same principle and initiated the well-known PetaJakarta.org project, which aims to map Jakarta (Indonesia) floods in near real-time using georeferenced flood-related 
tweets generated by citizens. Similarly, Li et al. [4] mapped the 2015 South Carolina floods using georeferenced flood-related tweets. But how accurate is this notion that the georeferenced location of a flood-related tweet corresponds to the actual location of the flooding event? Without this knowledge, it is difficult to ascertain the accuracy of flood maps created using georeferenced social media contents. Until now, what seems to be a consistent body of evidence in the literature is that disaster-related information on social media tends to come from people who are physically close to the disaster location, not necessarily in the exact disaster location [12], [13], [14], [15]. However, the extent to which physical closeness to flooding deviates from the actual locations of floods is not well known.

This study aims to improve understanding of the extent to which georeferenced locations of social media flood reports deviate from the actual locations of floods. In other words, it aims to investigate the level of accuracy expected with using georeferenced social media data for flood mapping. The study utilises flood-related tweets acquired as part of the PetaJakarta.org project implemented in the coastal mega-city of Jakarta, Indonesia. Flood-related tweets that contain both textual information about flood location and georeferenced location, i.e., the exact latitude/longitude coordinates from where the reports were sent, were retrieved for analysis. Further details about the analysis are provided in the methodology section.

\section{Methodology}

\section{A. Study Area: Jakarta, Indonesia}

The city of Jakarta was selected for this study because it is typical of coastal mega-cities of developing nations, which are in urgent need of innovative solutions to the problem of flood disasters [16]. Jakarta has a rapidly growing population of over 14 million people, most of whom suffer from the annual monsoonal floods that typically occur between the months of November and March [17]. The impacts of the frequent and high-intensity flooding events experienced in Jakarta are aggravated by a number of factors, including physical geography, climate change, poor maintenance of drainage network, land subsidence, sea-level rise, shortage of funding, aging and deteriorating flood control infrastructure, unplanned and rapid urban growth, slum dwellings and illegal disposal of solid waste in waterways [17]. The situation is further exacerbated by the lack of situational information needed to enable first responders and flood control operators make more informed operational decisions [16].

However, the city of Jakarta is also presented with a unique opportunity to harness crowdsourced social media data in better understanding and responding to the problem of flooding. Jakarta is home to millions of residents who are very active on social media sites, so much so that the city has been dubbed the world's "Twitter capital" [7]. In a mega-city context, these millions of residents potentially acting as human sensors during flooding events can contribute situational information in their localities via social media [18]. This combined with the government's strong promotion of social media as a means of communicating with citizens during disaster and emergency events provide a solid basis to explore the opportunity of harnessing social media data for improving flood situational awareness in Jakarta.

\section{B. The PetaJakarta.org System}

The PetaJakarta.org system is a social media-based mobile crowdsourcing application developed by the SMART Infrastructure Facility of the University of Wollongong, Australia in collaboration with Twitter Inc. and the DKI Jakarta Regional Disaster Management Agency (also known as BPBD DKI Jakarta) [8]. The PetaJakarta.org project aims to deliver a cost-effective approach for acquiring time-critical information needed to enable Jakarta citizens and government agencies gain improved situational awareness during extreme weather events such as flooding. The project implementation is based on a software application known as CogniCity, which is used to solicit, gather, sort, and map citizens' reports of real-time flood conditions posted on social media platforms such as Twitter [8]. Tweets are considered to be flood reports if they mention the word "flood" or "banjir" (in Bahasa Indonesian language). To ensure the acquired data are more reflective of ground truth, such reports must also originate from within Jakarta as determined by the city's geographical boundary. In essence, tweets referring to real-time flood conditions in Jakarta, but originating from outside the city are not captured. This is an important point to note, particularly as it accounts for the shortfall in PetaJakarta.org's datasets in relation to other work in the same study area [6], [7]. As part of the PetaJakarta.org campaign, users are requested to turn on geolocation feature on their mobile devices and also encouraged to send flood-related tweets, preferably ones with flood depth information and embedded photo of flood condition in their localities. Tweet reports received with geolocation metadata are used to create near real-time publicly accessible flood map that facilitates citizens' safe navigation through the city and also enables flood control operators and emergency services make more informed operational decisions.

\section{Analysis}

This study utilised the PetaJakarta.org dataset covering the 2014/2015 monsoon season. The dataset comprises 1,325 geolocated and 99,148 non-spatial tweets that were harvested using the keyword "flood" or "banjir". It has been reported that this "keyword-only" approach of harvesting disaster-related contents can be flawed by the presence of false positives associated with synonymous or connotative use of words within messages [7]. A hypothetical example of such false positive tweets, which do not relate to a flooding event, is "We are flooded with orders on our new product." Hence, to be more certain that the acquired tweets are actually reporting flood conditions, we further filter by retrieving only messages that contain flood depth information. According to Eilander et al. [7], this information can be determined by searching for tweets containing numbers immediately followed by "m" or "cm". Following this approach and excluding all retweets, we retrieved 189 geolocated and 556 non-spatial tweets that mentioned flood depth information in their messages. We focus on just the geolocated tweets as the aim is to understand the extent to which georeferenced locations of social media flood reports deviate from the actual locations of floods. 
In this study, we consider the actual locations of floods to be those referred to textually within the tweets. From the 189 flood-related georeferenced tweets, 80 (i.e., 42\%) contained textual information about flood location. This is consistent with previous report that $40 \%$ of flood-related tweets can be geolocated based on textual information [7]. 67 of the tweets (i.e., 84\%) referred to flood locations using the urban village name, popularly known as "kelurahan" in Jakarta. Eilander et al. [7] previously described the kelurahan as the main geographical entity in Jakarta that is often used within tweets to refer to areas of interest. From the 67 tweets that referred to locations by their kelurahan name, 15 (22.4\%) attempted to provide more precise location by giving the name of the subvillage, popularly known as community or Rukun Warga (RW) in Jakarta. Within each RW, there are smaller neighbourhoods known as Rukun Tetangga (RT). All except one of the tweets that provided specific information about RW also specified the RT. There are currently 267 Kelurahans, 2,728 RWs and 30,337 RTs in Jakarta [19]. Fig. 1 and Fig. 2 show the maps of Jakarta's Kelurahans and RWs respectively. Given the number and sizes of the RTs in Jakarta, RT is considered smaller than the minimum mapping unit (MMU) required for creating any meaningful flood map. Note that MMU in the context of flood mapping is the specific size of the smallest area (polygon) that can be meaningfully shown on a map. Kelurahan and RW therefore represent the smallest administrative units of analysis to map flooded areas in Jakarta. Spatial analysis using the Quantum Geographical Information System (QGIS) software showed that the average size of a Kelurahan is $2.48 \mathrm{~km}^{2}$ while that of an RW is $0.24 \mathrm{~km}^{2}$. In carrying out the analysis, we took the shortest distance between the georeferenced location of a tweet to the center of the RW or kelurahan where the flood is reported to have actually occurred. For each tweet, this distance represents the extent to which georeferenced social media flood report deviates from the actual location of flood. The results are presented in the following section.

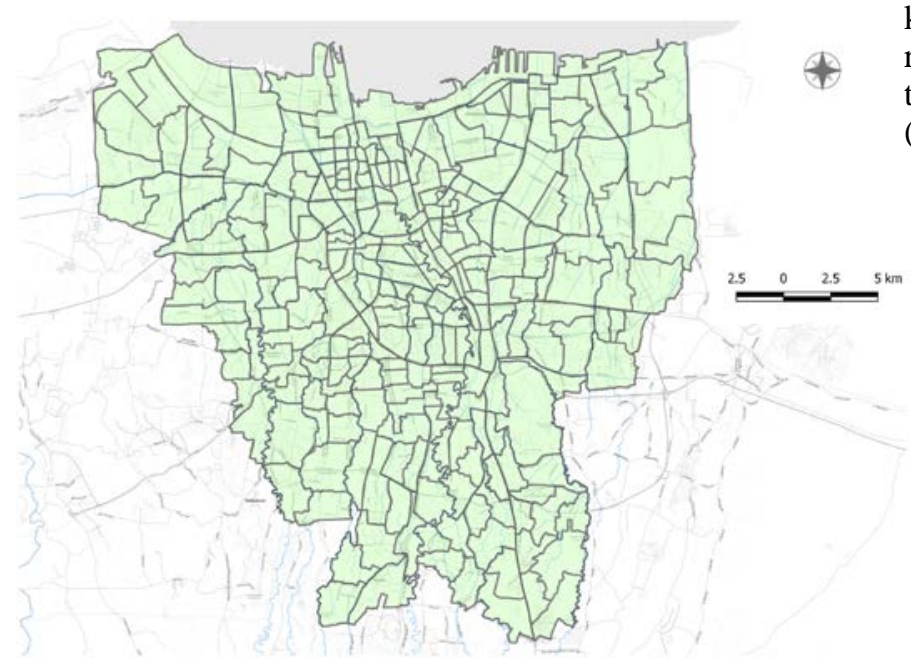

Fig. 1. Map showing Kelurahan in Jakarta (2015 dataset)

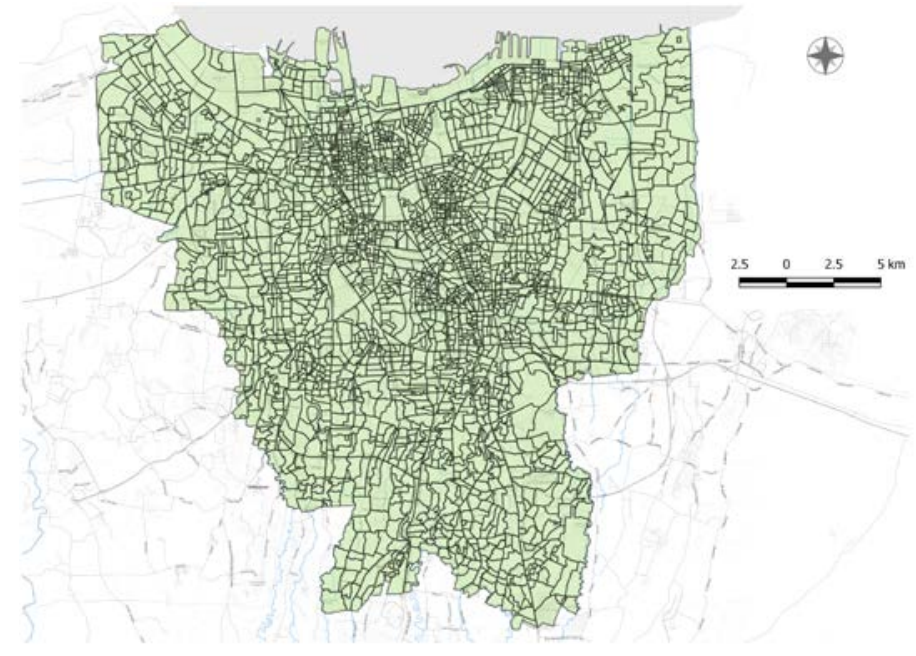

Fig. 2. Map showing Rukun Warga (RW) in Jakarta

\section{RESULTS AND DISCUSSIONS}

Within the 2014/2015 monsoon season investigated, there were 67 geolocated tweets containing flood depth information and textual reference to the village (Kelurahan) name. The results of the analysis revealed that 43 of these geolocated flood reports originated from the same village were the flood situation they reported about occurred. This represents $64.2 \%$ accuracy in using geolocated tweets to map flood conditions at an MMU equivalent to an urban village (Kelurahan) size. Recall that the average size of a Kelurahan in Jakarta is 2.48 $\mathrm{km}^{2}$. The remaining 24 flood reports, shown in Table 1, did not originate from the same village as the one in which the flood occurred. However, 8 of them (i.e., 12\% of the sample) were reported from a nearby village within $2 \mathrm{~km}$ to the actual village were the flood occurred. Another 7 geolocated tweets (see Table 1) were reported from far away villages, between 10 - 25 $\mathrm{km}$ away from the actual village were the flood occurred. This represents a $10.4 \%$ high-level inaccuracy in using geolocated tweets to map flood conditions at an MMU of an urban village (Kelurahan) size. 
Table1: Georeferenced tweets deviating from actual locations of flooding

\begin{tabular}{|c|c|c|}
\hline Georeferenced village & Actual village & $\begin{array}{c}\text { Distance } \\
\text { (km) }\end{array}$ \\
\hline MENTENG & CIKINI & 0.86 \\
\hline CIKINI & GONDANGDIA & 0.96 \\
\hline PEGANGSAAN DUA & KELAPA GADING TIMUR & 1.068 \\
\hline WIJAYA KESUMA & JELAMBAR & 1.08 \\
\hline BALE KAMBANG & PASAR MINGGU & 1.324 \\
\hline SEMPER TIMUR & CILINCING & 1.45 \\
\hline KEBON KOSONG & KEMAYORAN & 1.47 \\
\hline LAGOA & KOJA & 1.97 \\
\hline KAPUK MUARA & PEJAGALAN & 2.1 \\
\hline BAMBU APUS & SETU & 2.26 \\
\hline GUNUNG SAHARI UTARA & KEMAYORAN & 2.34 \\
\hline TUGU SELATAN & KOJA & 2.93 \\
\hline SEMPER BARAT & CILINCING & 2.93 \\
\hline KAPUK MUARA & PLUIT & 2.99 \\
\hline TAMBORA & JELAMBAR & 3.01 \\
\hline CENGKARENG BARAT & KAMAL & 4.4 \\
\hline ROROTAN & CILINCING & 4.8 \\
\hline KRUKUT & CENGKARENG BARAT & 10.557 \\
\hline KAYU PUTIH & PULO & 12.05 \\
\hline Outside Jakarta & SETU & 14.8 \\
\hline CENGKARENG BARAT & PULO & 16.3 \\
\hline CAKUNG TIMUR & PULO & 17.55 \\
\hline JELAMBAR & BARU & 19.6 \\
\hline MARUNDA & BARU & 25.06 \\
\hline \multicolumn{2}{|c|}{ Average distance from georeferenced village to actual village } & 6.41 \\
\hline
\end{tabular}

For improved flood mapping at the lowest possible MMU, we considered georeferenced tweets with textual reference to more precise flood locations based on sub-village or Rukun Warga (RW) names. The average size of an RW in Jakarta is $0.24 \mathrm{~km}^{2}$. RW is a more precise location description in Jakarta as compared to Kelurahan. However, only 15 tweets contained both RW and flood depth information for the 2014/2015 monsoon season investigated. In Jakarta, RWs are referred to by numbers (e.g., RW1, RW2, RW3, etc.) and are only unique within the village (Kelurahan) where they belong. In other words, two or more Kelurahan can have the same RW numbering (e.g., RW.4, Jati Pandang and RW.4, Cengkareng Barat). The implication is that any flood report with location description containing RW without village name is ambiguous and cannot be used for flood mapping. From the 15 tweets containing RW information, 2 were without village name and so were excluded from the analysis. Another 5 tweets originated from the same RW were the flood situation they reported about occurred. This represents 33.3\% accuracy in using geolocated tweets to map flood conditions at an MMU of sub-village (RW) size. The remaining 8 flood reports, shown cartographically in Fig. 3, originated from RWs different from the ones in which the flood occurred. However, half (i.e., 4) of these tweets were reported from a nearby RW within $1 \mathrm{~km}$ to the actual RW were the flood occurred and all except one of these 4 tweets were geolocated at the same village (Kelurahan) where the flood occurred. Contrarily, 2 of the 8 geolocated tweets were reported from far away RWs, between $10-16 \mathrm{~km}$ away from the actual RW were the flood occurred (see Fig. 3). This represents a $25 \%$ high-level inaccuracy in using geolocated tweets to map flood conditions at an MMU of subvillage (RW) size.

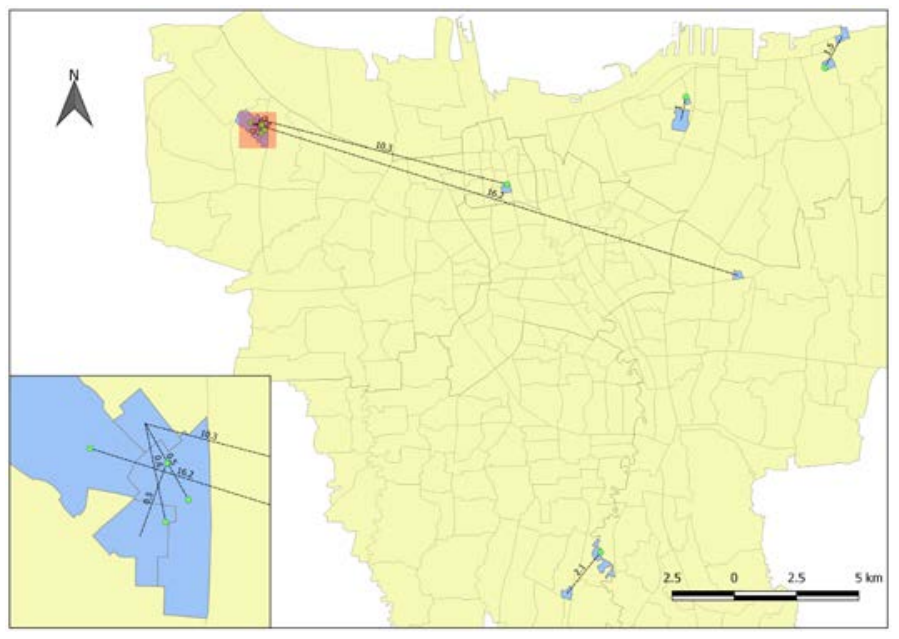

Fig. 3. Map showing distance of flood reports from actual RW where flood ocurred. The botton left rectangle is a zoomed in view of the highlighted rectangular area of the map.

More broadly, the results have revealed the extent to which georeferenced locations of social media flood reports deviate from the actual locations of floods. In other words, the results have provided insight into the level of accuracy expected with using georeferenced social media data for flood mapping. By assessing this accuracy both at the village (Kelurahan) and sub-village (RW) level, the study has revealed that the accuracy of flood maps generated with georeferenced social media data reduces with increase in the size of the MMU of the flood map. These findings question the usefulness of georeferenced social media data as a sole means of creating high-level accuracy flood maps. The PetaJakarta.org system aims to map floods using georeferenced social media data and its vigorous campaign expressly request users submitting flood reports to turn on the geolocation feature on their mobile devices. The results of this study have shown that for the 2014/2015 monsoon season investigated, the georeferenced-to-nonspatial tweet ratio for confirmed flood reports is 0.35 and the accuracy levels when using geolocated tweets to map flood conditions were $64.2 \%$ and $33.3 \%$ at MMUs of urban village (Kelurahan) and subvillage (RW) respectively. Geolocated flood reports with highlevel inaccuracy (i.e., greater than $10 \mathrm{~km}$ away from actual flood location) were $10.4 \%$ and $25 \%$ at MMUs of urban village (Kelurahan) and sub-village (RW) respectively. Jongman et al. [9] provided an important remark that partly accounts for these high-level inaccuracy observed with using geolocated tweets to map floods- if flood occurs in areas without internet access, as is often the case in developing nations, it can be expected that users will only be able to send tweet reports of their observations of flood conditions when they reach an area with internet access. Furthermore, social media users from very distant locations may share contents about flood conditions occurring elsewhere based on secondhand information received through other means.

Within the same period, i.e., the 2014/2015 monsoon season, the number of geolocated and non-spatial flood reports with water depth and textual information about flood location 
was 295, even without any vigorous campaign encouraging social media users to send flood reports containing such textual details. Apparently, this is the traditional way citizens communicate about disaster risks; a text message refering to unfolding disaster would often include explicit reference to its location in order to be complete. One would imagine that with campaigns clearly directing and encouraging social media users to provide textual information about flood locations (e.g. exact RW and Kelurahan), there will even be increased availability of data to create accurate flood maps on this basis. Hence, for improved locational accuracy, we recommend that future campaigns and applications of crowdsourced social media data explore the use of textual location information as means of flood mapping rather than georeferenced location. Eilander et al. [7] recently explored the use of tweets with textual locational information in creating flood maps for Jakarta at an MMU of urban village (Kelurahan). However, the approach could only produce probabilistic maps that apply to pluvial flooding, but not fluvial floods [7].

\section{A. Recommendations}

As a way forward, we recommend a near real-time deterministic flood mapping strategy with high level location accuracy that works for any type of flood, based on floodrelated social media contents containing textual location information of the smallest administrative unit suitable for creating meaningful flood maps. In the case of Jakarta, the smallest administrative unit for flood mapping purpose is RW and a strategy is required to improve data availability required for mapping at this level. The proposed strategy is based on a participatory approach to urban data collection, where key representatives in each administrative unit are selected, properly motivated and equipped with the right knowledge and tools to share situational information in their local communities during flooding events. Current social media based approaches for creating near real-time deterministic flood maps are flawed by an assumption that the absence of a flood report in an area means there is no flood in that area [4], [8], [11]. This may not always be the case. The proposed strategy can address this issue by requesting and alerting all community representatives to provide situational information in their localities during specified time windows so that the overall flood situation in the city can be ascertained and mapped at those set times. Other citizens' flood reports shared on social media can be used to complement the process. Interestingly, Jakarta has a public administrative/leadership structure that makes it easy to operationalize the proposed strategy. Each RW in Jakarta has a head that can act as a community representative to send flood reports. This role can be supported by other neighborhood leaders (also known as RT heads) existing within each RW. These RW/RT heads are already being paid to represent their communities and neighborhoods during key events [20]. There has also been a new policy in Jakarta obliging and paying RT and RW heads to use a government monitoring application known as Qlue in reporting about key issues occurring within their neighborhood or community at least three times daily [20]. Henceforth, what is required is to ensure RT/RW heads are adequately motivated and guided on how and when to provide flood-related information.

\section{B. Limitation}

One limitation of this study is the lack of additional data (e.g. official flood maps or rainfall data for specific days that correspond to tweets of interest). This data could have been useful for validating the accuracy of textual information about flood locations as contained within tweets. Given that most tweets also contain photos of flood conditions, another potential data source for validating the accuracy of textual information about flood locations provided in tweets is the geotag in the metadata of the photo i.e., the exact longitude/latitude coordinate where the photo was taken. Unfortunately, this metadata embedded in an image file, known as EXIF (Exchangeable Image File) data, is programmatically removed by Twitter and other popular social media sites prior to upload, due to user privacy and other business concerns. Fohringer et al. [21] have initiated the idea of validating locations of flood using the place and context depicted within the actual photos that are embedded in social media (Flickr and Twitter) contents, but they acknowledged that more robust means are required to visually explore and derive meaningful information in real-time from such photos.

\section{CONCLUSION}

Georeferenced social media data are increasingly being used as a basis for near real-time flood mapping, particularly in data-starved regions. The underlying assumption is that the georeferenced locations of flood-related social media messages correspond to exact or near locations to where floods occur. By analyzing flood-related tweets acquired as part of the PetaJakarta.org project implemented in the coastal mega-city of Jakarta, this study has provided insight into the level of accuracy expected when using georeferenced social media data to map urban floods. The study investigated the extent to which georeferenced social media flood report deviates from the actual location of flood by calculating the shortest distance between the georeferenced location of a tweet to the center of the locality or area that is actually been reported to have flooded. It was observed that the accuracy of flood maps generated with georeferenced social media data reduces with increase in the minimum mapping unit (MMU) of the flood map. MMU, in the context of flood mapping, is the specific size of the smallest area (polygon) that can be meaningfully shown on a map. In the study area- Jakarta, Kelurahan and RW were considered appropriate as MMUs because they represent the smallest administrative units of analysis to reasonably map flooded areas in Jakarta. Following the results of this study, a strategy has been recommended that would potentially enable data-starved coastal megacities to achieve more accurate flood mapping using crowdsourced social media data. The recommended strategy is suitable for generating near real-time deterministic flood maps, irrespective of the type of flood. It also eliminates the errors that arise from assuming that an area is unflooded just because there is no social media flood report from that area.

\section{ACKNOWLEDGMENT}

This work was funded under the auspices of the Australian National Data Service (ANDS) through the National Collaborative Research Infrastructure Strategy Program 
[ANDS MODC 15, 2014], the Department of Foreign Affairs and Trade, Australia (DFAT 2014) [Agreement Number 71984], Twitter Data Grant (2014) and the University of Wollongong Global Challenges Program Seed Funding (2014) and Challenges Grant (2015).

\section{REFERENCES}

[1] B. Adame and C. H. Miller, "Vested interest: developing scales for assessing flooding preparedness", Disaster Prevention and Management, vol. 25, no. 3, pp. 282-297, 2016.

[2] G. Di Baldassarre, G. Schumann, P.D. Bates, J.E. Freer and K.J. Beven, "Flood-plain mapping: a critical discussion of deterministic and probabilistic approaches", Hydrological Sciences Journal-Journal des Sciences Hydrologiques, vol. 55, no. 3, pp. 364-376, 2010.

[3] E. Opolot, "Application of remote sensing and geographical information systems in flood management: a review", Research journal of applied sciences engineering and technology, vol. 6, no. 10, pp. 1884-1894, 2013.

[4] Z. Li, C. Wang, C.T. Emrich and D. Guo, "A novel approach to leveraging social media for rapid flood mapping: a case study of the 2015 South Carolina floods", Cartography and Geographic Information Science, pp. 114 , http://dx.doi.org/10.1080/15230406.2016.1271356

[5] J. Sanyal and X.X. Lu, "Application of remote sensing in flood management with special reference to monsoon Asia: a review", Natural Hazards, vol. 33, no. 2, pp.283301, 2004.

[6] T. Brouwer, "Potential of Twitter derived flood maps: comparing interpolation methods and assessing uncertainties", (Master's thesis, University of Twente), 2016.

[7] D. Eilander, P. Trambauer, J. Wagemaker and A. van Loenen, "Harvesting social media for generation of near real-time flood maps", Procedia Engineering, vol. 154, pp.176-183, 2016.

[8] T. Holderness and E. Turpin, "From Social Media to GeoSocial Intelligence: Crowdsourcing Civic Comanagement for Flood Response in Jakarta, Indonesia", In Social media for government services, pp. 115-133, Springer International Publishing, 2015.

[9] B. Jongman, J. Wagemaker, B.R. Romero and E.C. de Perez, "Early flood detection for rapid humanitarian response: harnessing near real-time satellite and Twitter signals", ISPRS International Journal of Geo-Information, vol. 4, no. 4, pp. 2246-2266, 2015.

[10] T. Brouwer, D. Eilander, A. van Loenen, M.J. Booij, K.M. Wijnberg, J.S. Verkade and J. Wagemaker, "Probabilistic flood extent estimates from social media flood observations", Natural Hazards and Earth System Sciences, vol. 17, no. 5, pp. 735-747, 2017.
[11] M. Graham, A. Poorthuis A and M. Zook, "Digital trails of the UK floods - how well do tweets match observations?", The Guardian, 2012, Retrieved June 12, 2017, from https://www.theguardian.com/news/datablog/2012/nov/28 /data-shadows-twitter-uk-floods-mapped.

[12] J.P. De Albuquerque, B. Herfort, A. Brenning and A. Zipf, "A geographic approach for combining social media and authoritative data towards identifying useful information for disaster management", International Journal of Geographical Information Science, vol. 29, no. 4, pp.667-689, 2015.

[13] B. Herfort, S.J. Schelhorn, J.P. De Albuquerque and A Zipf, "Does the spatiotemporal distribution of tweets match the spatiotemporal distribution of flood phenomena? A study about the River Elbe Flood in June 2013", In International Conference on Information Systems for Crisis Response and Management, The Pennsylvania State University, May 2014.

[14] Y. Kryvasheyeu, H. Chen, N. Obradovich, E. Moro, P. Van Hentenryck, J. Fowler and M. Cebrian, "Rapid assessment of disaster damage using social media activity", Science Advances, vol. 2., no. 3, 2016 , p.e1500779. doi:10.1126/sciadv.1500779.

[15] S. Vieweg, A.L. Hughes, K. Starbird and L. Palen, "Microblogging during two natural hazards events: what twitter may contribute to situational awareness", In Proceedings of the SIGCHI conference on human factors in computing systems, pp. 1079-1088, ACM, April 2010.

[16] R. Ogie, T. Holderness, M. Dunbar and E. Turpin "Spatio-topological network analysis of hydrological infrastructure as a decision support tool for flood mitigation in coastal mega-cities". Environment and Planning R: U Jrhan Analytics and City Science, vol. 44, no. 4, pp.718-739, 2017.

[17] R.I. Ogie, S. Dunn, T. Holderness and E. Turpin, "Assessing the vulnerability of pumping stations to trash blockage in coastal mega-cities of developing nations", Sustainable Cities and Society, vol. 28, pp. 53-66, 2017.

[18] R.I. Ogie, "Adopting incentive mechanisms for largescale participation in mobile crowdsensing: from literature review to a conceptual framework", Humancentric Computing and Information Sciences, vol. 6, no. 24, pp. 1-31, 2016. DOI: 10.1186/s13673-016-0080-3.

[19] C. Elyda, "Jakarta to increase allowances for neighborhood, community unit heads", Jakarta Post, 2017, Retrieved June 15, 2017, http://www.thejakartapost.com/news/2017/02/03/jakartato-increase-allowances-for-neighborhood-communityunit-heads.html.

[20] A. Anya, "Do people still need RT/ RW heads?", Jakarta Post, 2016, Retrieved June 19, 2017, http://www.thejakartapost.com/news/2016/06/02/dopeople-still-need-rt-rw-heads.html.

[21] J. Fohringer, D. Dransch, H. Kreibich and K. Schröter 2015. "Social media as an information source for rapid flood inundation mapping", Natural Hazards and Earth System Sciences, vol. 15, no. 12, pp. 2725-2738, 2015. 